\title{
Improving the Quality of Welded Joints in Laser Welding of Silver Products
}

\author{
T.N. Borovik
}

\begin{abstract}
The article deals with promising areas of application of pulsed laser welding for products made of silver-based alloys. The results of experimental studies on the choice of modes of pumping, defocusing to improve the quality of the weld and the efficiency of the welding process.
\end{abstract}

Index Terms: weld quality, silver alloys, pulsed laser welding, defocusing, pumping modes

\section{INTRODUCTION}

Currently, there are many products that are of great value for the cultural heritage of our country and the world as a whole. A certain number of antique items containing silver details and paying tribute to the time need restoration. Unfortunately, silver is a corrosion-resistant metal, and when interacting, for example, with hydrogen sulfide, which is often in the form of an impurity contained in the ambient air, forms sulfur compounds, the so-called "mobile". Some art products, which have been lying for quite a long time, are sometimes thoroughly imbued with black. During the restoration of these old products are trying to preserve their original appearance and design, without replacing it with a "new model", so the choice of restoration method is crucial to preserve the historical and artistic value of the restored things.

Revised Manuscript Received on July 09, 2019.

T.N. Borovik, Assistant Professor, MIREA-Russian Technological University, 119454, Russiaborovik@mirea.ru

\section{MATERIAL AND METHODS}

Today use various ways of restoration and connection of elements of a product, the main of which are soldering, gluing and mechanical ways of connection by means of technological brackets and rivets.

Based on the fact that jewelry and some other artistic products were manufactured and continue to be produced mainly by means of high-temperature soldering, a significant part of the restoration work is now also produced by high-temperature soldering with silver solders. When soldering due to the high thermal conductivity of silver, all the product is usually heated to a high temperature, and this in some cases is incompatible with the presence of any decorative non-metallic materials (enamel, stones, etc.) in the product.

The method of pulsed laser welding allows performing connection operations in close proximity to enamels, stones and other heat-sensitive decorative elements. This is due to such technological features of the method as the minimum total heat input into the welded materials; a slight thermal effect on the metal of the near-weld zone; small thermal deformation of the welded elements; the possibility of obtaining unobtrusive welds of small sizes with sufficiently high strength characteristics; the ability to conduct the connection process not only in the fusion welding mode, but also in the soldering-welding mode, which allows you to connect a wider range of metals and alloys.

The use of fusion welding of silver is associated with its specific physical properties: due to the large thermal conductivity requires the use of concentrated heat sources and preheating up to 500-6000C, due to the high coefficient of thermal expansion of silver and its alloys can be significant stress and deformation of the product.

Welding of silver alloys containing copper, aluminum, silicon, cadmium is also complicated by the tendency of these elements to oxidation. The oxidation of alloying elements is dramatically reduced plasticity and increased strength.

Thus, when creating and repairing silver products and its alloys, it is obviously necessary to use energy sources with the highest possible energy density in the heating zone, which currently determines the laser as the most suitable technological energy source for this case.

To date, the list of art metal products is extremely wide: from weapons, Cutlery, jewelry to exquisite works of art, in which the metal is combined with precious stones and enamel. Refined look of a product that combines rock-metal, for example, the filigree on the stone, where stone is the background color for the 
ornamental patterns of the metal.

For expensive unique products before and now use metals such as gold, silver, bronze with inserts of precious and semiprecious stones: agate, carnelian and others.

With regard to the production of art products and restoration work, the technology of pulsed laser welding can be used in several directions. For example, in the design of jewelry there is a possibility of Assembly-welding fragments of products after fixing stones, enamels or other decorative coatings.

To obtain a high-quality connection, the power density and the accuracy of the radiation guidance are crucial, since the destruction occurs when the beam of an optical quantum generator hits the surface of a stone, for example, agate.

Agate can have both opaque and translucent areas. The destruction of translucent agate zones begins at a power density exceeding $0.8 * 105 \mathrm{~W} / \mathrm{cm} 2$ and is a chip or crack located under the polished surface of the stone. With a further increase in the power density, the size of the crack increases. The crack comes to the surface, and the fragments of the stone are separated. The direction of crack development and its location on the irradiation site cannot be predicted. The destruction of opaque areas begins at lower irradiance densities (figure 1) and covers larger areas. A further increase in the power density leads to the release of stone fragments from the irradiation zone and the formation of a crater. No melting of the crater walls was detected. Probably, the high rate of heating causes such a rate of growth of elastic stresses in the stone that the development of cracks and the release of breakaway fragments occur almost simultaneously.

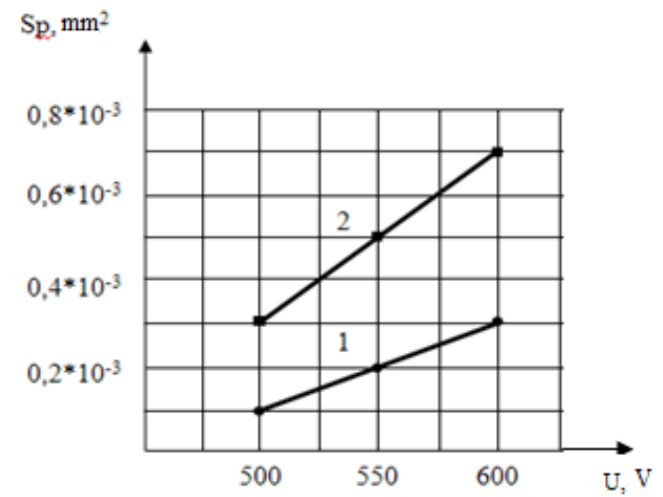

Figure 1 - the effect of optical quantum generator radiation on the size of the destruction zone of jewelry stones: 1 -

translucent agate; 2 - opaque agate

Destruction of stones inserts on the products in the performance of welding operations is possible in the event that part of the beam directed to the point of connection will fall on the surface of the stone. This is possible in the following cases:

- the diameter of the connected part is less than the diameter of the beam;

- the axis of the beam is shifted from the metal part towards the stone more than the permissible value (aiming accuracy); - on the surface of the stone gets a beam of optical quantum generator reflected from the metal surface of the part.

\section{RESULTS AND DISCUSSION}

For the analysis we choose several types of stones (polished): Jasper, amazonite, agate.

When defocusing is equal to 0 , changing the voltage of the pump exposed to individual points of the surface of the stone. Then we analyze the experience with a microscope. Based on the experiments, we build a graph.

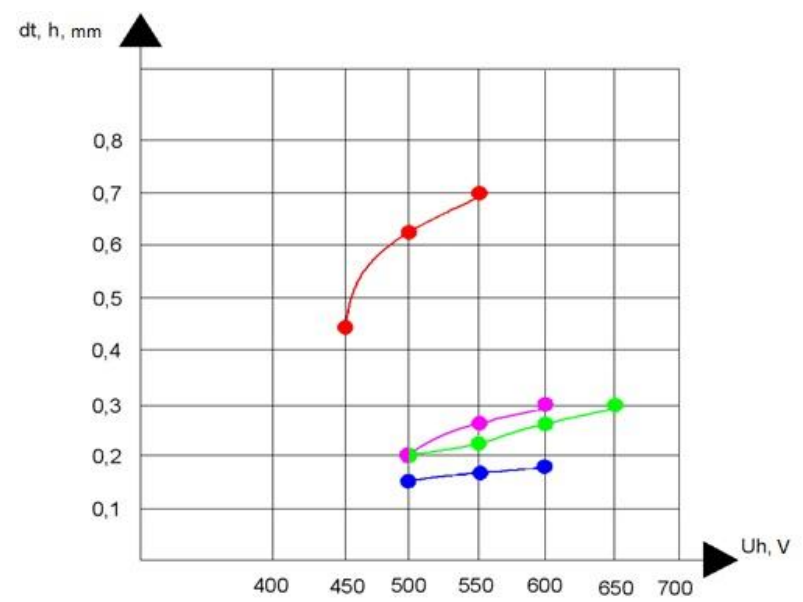

Figure 2 - Graph of the dot diameter of the stones from the voltage pump.

Red - Jasper, blue - opaque agate, green - amazonite, purple transparent agate.

As a result of the study of the effect of laser radiation on the surface of the stones, with a change in the pumping voltage from $425 \mathrm{~V}$ to $600 \mathrm{~V}$, it was found that the diameter of the destroyed surface area increases from $0.16 \mathrm{~mm}$ to $0.7 \mathrm{~mm}$. We calculate the minimum power density that causes the destruction of the stone surface:

$$
q=\frac{E}{t \cdot S}
$$

where $E$ - radiation energy, $t$ - time, $t=4 \cdot 10^{-3}, S-$ square, $S=\pi \cdot D^{2} / 4$.

We calculate the minimum power density for different pump voltages, summarizing the results in the table.

Table 1 - results of calculation of the minimum power density for different pump voltages

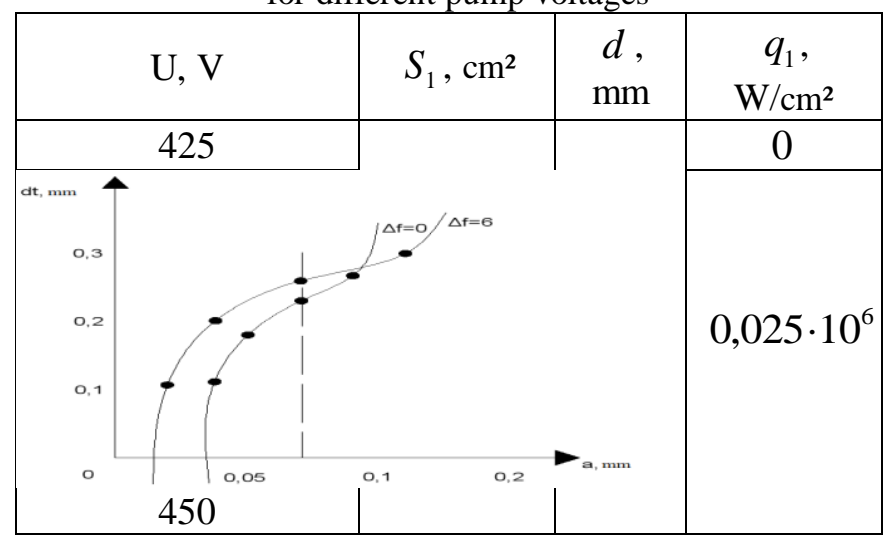




\begin{tabular}{|c|c|}
\hline 500 & $0,1 \cdot 10^{6}$ \\
\hline 550 & $0,18 \cdot 10^{6}$ \\
\hline 600 & $0,25 \cdot 10^{6}$ \\
\hline 650 & $0,34 \cdot 10^{6}$ \\
\hline
\end{tabular}

Figure 3 - results of the experiment

To study the accuracy of laser guidance, take a silver sample with a cross section of $5 \times 0.5 \mathrm{~mm}$, place it on the surface of the stone and direct the radiation along the plate, shift it to the stone, with defocusing 0 and 3. Evaluation of the study is carried out under a microscope.

When defocusing $a=0, b=0.22 \mathrm{~mm}$, the point where the beam hits part of the stone, has a light trace of radiation.

When defocusing $\mathrm{a}=3, \mathrm{~W}=0.25$, the beam falling partially on the stone destroys it, completing the round shape of the point. The greater the hit on the stone, the more damage on it (stratification, destruction under the plate).

\section{CONCLUSION}

The proposed method of studying the accuracy of radiation guidance allows us to determine the range of deviation of the beam axis, ensuring the absence of damage to the stone [1-10].

Found that the stress of pumping optical quantum generator $600 \ldots 650$ To the axis of the beam must not be closer than $0.4 \mathrm{~mm}$ from the edge because a further shift in the direction of the stone causing it to crumble and to prevent the destruction of the stone, the distance of the center of radiation of the metal must be greater than $0.1 \mathrm{~mm}$. the increase in the defocusing causes the need to increase the axis distance of the beam from the edge by $20 . . .25 \%$.

The study established that the laser radiation on the surface of the stones causes the destruction, the magnitude of which depends on the power density.

\section{REFERENCES}

[1] Struchenkov V.I. Computer Technologies In Line Structure Routing // Russian Technological Journal, 2017. Volume 5, Issue 1, P. 29-41. URL: https://rtj.mirea.ru/upload/medialibrary/9b4/rtzh_2017_1_29_41.pdf

[2] Borovik T.N., Yampolskii V.M., Krasheninnikov A.I. Design repaired products from alloys based on silver with the use of laser welding // Design. Theoryand Practice, 2012, 10, p. 32-44.

[3] Borovik T.N., Belousov I.V. Influence of technological factors on the quality of joints in pulsed laser welding // Research: theory, methods and practice: materials of the International scientific-practical conference», 2017. - p. 271-273. - ISBN 978-5-9500297-4-5

[4] Borovik T.N., Belousov I.V. The effect of defocusing on the occurrence of burns in pulsed laser welding of silver // Research: theory, methods and practice: materials of the International scientific-practical conference, 2017. - p. 220-221. - ISSN 2412-0537.

[5] Borovik T.N., Belousov I.V. Practical application in the educational environment of modern technologies in the field of materials // Educational environment today: theory and practice: materials of the International scientific-practical conference. 2017. - C. 77-78. - ISBN 978-5-9500127-8-5.

[6] Askretkov A.D., Koryakov A.G. The Some Economic Aspects Of Production Of Pharmaceutical Substance Hydroxyethyl Starch In Small Industrial Scale // Russian Technological Journal, 2018. Volume 6, Issue 1, P. 53-62. URL:

[7] https://rtj.mirea.ru/upload/medialibrary/587/RTZH_2018_1_53_62.pdf
[8] Djevello E.S., etc. Specifics of Management Quality Implementation to Information Systems and Products // Proceedings of the 2018 International Conference "Quality Management, Transport and Information Security, Information Technologies", IT and QM and IS, 2018, 8524995, p. 40-43.

[9] Cheremukhina Y.Y., etc. The process of working with claims in the quality management system of an enterprise of the radio-electronic industry // International Journal of Engineering and Technology(UAE). 2018. Volume 7, Issue 4.36. P. 67-68.

[10] Nazarenko M.A., etc. Main directions of higher education regionalization process as an integral part of social partnership in society (The problems of inclusive education) // International Journal of Engineering and Technology(UAE). 2018. Volume 7, Issue 4.36. P. 1135-1138.

[11] Sukhorukova S.M., Pogorelyi A.M. How To Ensure Environmental And Industrial Safety In Space Exploration? // Russian Technological Journal, 2017. Volume 5, Issue 1, P. 57-63. URL: https://rtj.mirea.ru/upload/medialibrary/560/rtzh_2017_1_57_63.pdf 